\title{
Managing Stakeholder Interests in a Nonprofit Setting: Who Matters Most? An Abstract
}

\author{
Kelly Weidner and Anjali Bal
}

\begin{abstract}
Increasingly, firms are adopting what is known as a stakeholder perspective in how they conduct business. In the business community, it was previously common for managers to believe that the primary stakeholder of the firm is the owner (shareholder) and therefore serving the customer in the most profitable way possible was best. However, in our rapidly changing marketplace, managers are finding that addressing multiple stakeholder groups is essential to being successful. Take, for example, consumers' growing interest in issues related to sustainability. To remain competitive, firms have therefore adopted a stakeholder interest that encompasses not only the financial objectives of the business but also the social interests of various stakeholder groups and the environmental interests of the community in which it operates.

This paper examines how a nonprofit organization can have trade-offs between multiple stakeholder groups that have varying interests, some of which are in direct conflict with one another.
\end{abstract}

K. Weidner $(\bowtie)$

Saint Mary's College of California, Moraga, CA, USA

e-mail: klw7@stmarys-ca.edu

\author{
A. Bal \\ Babson College, Wellesley, MA, USA \\ e-mail: abal@babson.edu
}

